\title{
Tsafon
}

Revue d'études juives du Nord

$75 \mid 2018$

Exil des langues - Langues d'exil

\section{Laurent Joly, Dénoncer les juifs sous l'Occupation}

\section{Danielle Delmaire}

\section{(Q) OpenEdition}

\section{Journals}

Édition électronique

URL : https://journals.openedition.org/tsafon/717

DOI : $10.4000 /$ tsafon. 717

ISSN : 2609-6420

\section{Éditeur}

Association Jean-Marie Delmaire

\section{Édition imprimée}

Date de publication : 1 juin 2018

Pagination : 183-184

ISSN : 1149-6630

\section{Référence électronique}

Danielle Delmaire, «Laurent Joly, Dénoncer les juifs sous l'Occupation», Tsafon [En ligne], 75 | 2018, mis en ligne le 06 mai 2019, consulté le 24 juin 2021. URL : http://journals.openedition.org/tsafon/717 ; DOI : https://doi.org/10.4000/tsafon. 717

Ce document a été généré automatiquement le 24 juin 2021.

Tsafon. Revues d'études juives du Nord 


\title{
Laurent Joly, Dénoncer les juifs sous l'Occupation
}

\author{
Danielle Delmaire
}

\section{RÉFÉRENCE}

Laurent Joly, Dénoncer les juifs sous l'Occupation, Paris, CNRS éditions, 2017, 231 p., $22 €$

Directeur de recherches au CNRS, Laurent Joly a travaillé abondamment sur le sort des juifs durant la guerre, a soutenu une thèse sur le Commissariat général aux questions juives puis a étendu son champ de recherches à l'extrême droite. Son dernier ouvrage vient compléter un corpus déjà bien épais. D'emblée, il présente son travail comme pionnier précisant que le sujet n'a jamais été abordé pour lui-même. On ne peut lui contester cette remarque car, en effet, comme il l'affirme, l'ouvrage d'André Halimi : La délation sous l'occupation (A. Moreau, 1983) souffre d'abondantes erreurs. En outre, si des études ont évoqué les dénonciations, certaines sont, selon lui, «contestées et contestables ».

2 Si le sujet est encore peu travaillé, c'est qu'il est brûlant et que l'historiographie s'est d'abord intéressée aux victimes puis aux bourreaux. De plus, les archives de la Seconde Guerre mondiale ne se sont largement ouvertes qu'au tournant des années 1990-2000. En outre, pour ce qui concerne la collaboration et la délation, pendant de longues années, voire des décennies, les chercheurs se sont heurtés à une législation prudente et tatillonne, qui voulait protéger les descendants des collaborateurs dont il fallait taire les noms. Ce temps est révolu, récemment, et Laurent Joly en profite pour le bonheur des historiens.

3 Toutefois, l'ouvrage ne concerne que la région parisienne (comme le précise le soustitre) et l'auteur eut déjà fort à faire avec le dépouillement des dossiers judiciaires ouverts après la guerre, avec la lecture des lettres envoyées aux diverses instances françaises ou allemandes chargées de la traque des juifs. 
L'auteur présente ces différents services dépendant du CGQJ, « véritable ministère de l'antisémitisme ", dirigé par Xavier Vallat et Darquier de Pellepoix, aidé par un triste sire, Joseph Antignac, subalterne mais efficace pour harceler les juifs. La brigade Permilleux et la préfecture de police ne furent pas en reste. Qui sont les délateurs ? Des voisins très souvent, des collègues ou confrères, assouvissant une vengeance, dénouant une querelle. Si des concierges ont accepté de recueillir des fugitifs, d'autres se sont empressés de dénoncer des résidents de leur immeuble. C'est très souvent la jalousie, la crapulerie ou l'avidité du gain qui motivent les dénonciateurs. Ils agissent par des lettres envoyées aux administrations mises en place pour chasser les juifs mais ils utilisent aussi la presse : Le Pilori, de l'ancien antidreyfusard Jean Drault, se spécialisant dans les annonces dénonciatrices et meurtrières. Des exemples précis abondent au fil de cette étude, un récit qui se termine inexorablement par la déportation de la victime "sans retour»! La dénonciation a tué Cypa Holeman victime d'un escroc; le mannequin Bella Ariel; Annette Zelman arrêtée à l'initiative du médecin renommé Hubert Jausion, père de son fiancé, le poète Jean Jausion. Des actes aux conséquences tragiques! «La délation est partie prenante de la politique génocidaire » (p. 18) assène Laurent Joly. Elle est le premier pas, avant le passage à Drancy ou autres prisons, vers la mort.

Quel fut le sort des délateurs à la Libération ? Ils n'avaient pas dénoncé des résistants, ce qui au lendemain de la guerre était une faute plus grave que la dénonciation des juifs, et les rescapés étaient trop peu nombreux pour réclamer justice. Mais il y eut quand même des arrestations et des enquêtes qui ont nourri cette étude. Trois condamnations à mort ont été prononcées, plus souvent ce sont des réclusions et des travaux forcés qui ont sanctionné ces dénonciations. Et l'on reste confondu par l'absence de remords de quelques délateurs, niant toute culpabilité dans le sort mortel réservé à leurs victimes. Telle cette Madame Bonnefoy (la mal nommée !) qui s'insurge contre son arrestation tant elle est convaincue «d'avoir raison » pour en finir avec la nocivité des juifs (p. 83). 